\title{
Ecophysiology modeling by artificial neural networks for different spacings in eucalypt
}

Bruno Oliveira Lafetá ${ }^{*}$, Reynaldo Campos Santana², Gilciano Saraiva Nogueira², Tamires Mousslech Andrade Penido², Diego dos Santos Vieira²

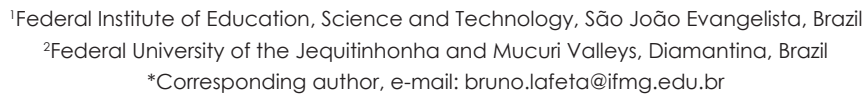

\begin{abstract}
Growth and production models are widely used to predict yields and support forestry decisions. Artificial Neural Networks (ANN) are computational models that simulate the brain and nervous system human functions, with a memory capable of establishing mathematical relationships between independent variables to estimate the dependent variables. This work aimed to evaluate the efficiency of eucalypt biomass modeling under different spacings using Multilayer Perceptron networks, trained through the backpropagation algorithm. The experiment was installed in randomized block, and the effect of five planting spacings was studied in three blocks: T1 - $3.0 \times 0.5 \mathrm{~m}$; T2 - $3.0 \times 1.0 \mathrm{~m}$; T3-3.0 x $1.5 \mathrm{~m}$; T4-3.0 × $2.0 \mathrm{~m}$ e T5-3.0 $3.0 \mathrm{~m}$. A continuous forest inventory was carried out at the ages of $48,61,73,85$ and 101 months. The leaf area, leaf perimeter and specific leaf area were measured at 101 months in one sample tree per experimental unit. Two thousand ANN were trained, using all inventoried trees, to estimate the eco-physiological attributes and the prognosis of the wood biomass. The artificial neural networks modeling was adequate to estimate eucalypt wood biomass, according to age and under different spacings, using the diameter-at-breast-height and leaf perimeter as predictor variables.
\end{abstract}

Keywords: wood biomass, planting density, ecophysiology, artificial intelligence, prognosis

\section{Introduction}

Clean energy production from forest biomass is a sustainable alternative to fossil fuels (non-renewable). Technological advances that aim to increase productivity are necessary and provide subsidies in choice of the most adapted genetic material, better planting methods, conducting and harvesting a forest stand.

Dry matter accumulation is an integrated measure of plant physiological performance over time (Merchant et al., 2010). The correlation of this accumulation with photosynthesis indicates that it is able to express competition for space, nutrients, water, solar energy, temperature, carbon dioxide, utilization efficiency of these

resources and interaction among them (Almeida et al., 2007; Montaldo et al., 2008; Costa et al., 2009).

Biomass quantity and quality can be affected by competition imposed by the planting spacing. Greater initial biomass production by area is expected in more densely planted and growth stagnation occurs at younger ages, due to intensification of resource utilization. Throughout the rotation, differences in growth between different densities tend to be minimized (Campos \& Leite, 2013).

Growth and production models are widely used to predict yields and assist silvicultural decision making. Mechanistic models (or process 
models) are flexible to certain environmental characteristics, encompassing growth trends and biological assumptions (Miehle et al., 2009; Campos \& Leite, 2013). These models provide estimates of forest productivity by weighing the influence of environmental factors (Almeida et al., 2007). The leaf area, specific leaf area and perimeter are eco-physiological parameters that influence photosynthetic capacity and leaves respiration (Alcorn et al., 2008; Montaldo et al., 2008; Ferreira et al., 2016), besides being useful to characterize plant adaptations to environmental conditions. Among these, specific leaf area is routinely used in prediction models, such as 3-PG (Physiological Processes Predicting Growth) and CABALA (Nouvellon et al., 2010).

As alternative to traditional regression modeling, Artificial Neural Networks (ANNs) are composed of a massive parallel system integrated of simple processing units (artificial neurons), which calculate certain mathematical functions and allow to generalize assimilated knowledge to unknown data (Gorgens et al., 2009; Binoti, 2010; Binoti et al., 2015; Zanuncio et al., 2016). For the training of multilayer perceptron networks (multilayer), traditionally, backpropagation algorithm is adopted to optimize predictive capacity. This algorithm extends network's ability to solve non-linearly separable problems (Braga et al., 2007).

This work aimed to evaluate the efficiency of eucalypt biomass production modeling under different spacings using artificial neural networks technique.

\section{Material and Methods}

This work was conducted in Itamarandiba municipality - MG, at $17^{\circ} 50^{\prime}$ south latitude and $42^{\circ} 49^{\prime}$ west longitude, Aperam Bioenergia area. The predominant climate in region is classified as Cwa by Köppen international system (Köppen, 1936), with mild and dry winters and hot, rainy summers. The dry season is well defined, from April to September, with a monthly water deficit of 30 to $50 \mathrm{~mm}$ (INMET, 2010). Annual averages of rainfall and temperature are 1,160 $\mathrm{mm}$ and $20^{\circ} \mathrm{C}$, respectively (Pulrolnik et al., 2009).

The experiment was installed in December 2002 using a hybrid of Eucalyptus grandis W. Hill ex Maiden x E. camaldulensis Dehnh, on flat relief terrain, Red-Yellow Latosol and at 1,097 $\mathrm{m}$ altitude. The design was in three random blocks. The treatments consisted of the following planting spacings: $\mathrm{Tl}-3.0 \times 0.5 \mathrm{~m}$; T2 - $3.0 \times 1.0 \mathrm{~m} ; \mathrm{T} 3-3.0 \times 1.5 \mathrm{~m} ; \mathrm{T} 4-3.0 \times 2.0 \mathrm{~m}$ and T5 $-3.0 \times 3.0 \mathrm{~m}, 3 \mathrm{~m}$ was the fixed distance between planting lines. Each experimental unit was defined as six lines with 28 trees, totaling 168 individuals, of which 48 were measured, due to adoption of double border.

A continuous forest inventory was carried out at the ages of 48, 61, 73, 85 and 101 months. The Diameter-at-Breast-Height overbark (DBH - at height of $1.30 \mathrm{~m}$ from the ground, $\mathrm{cm}$ ) and total Height $(\mathrm{H}, \mathrm{m})$ of all trees were measured. At 101 months, 50 trees were felled in each spacing for rigorous cubage up to commercial height (diameter $4 \mathrm{~cm}$ ), distributed in classes with regular intervals of $5 \mathrm{~cm} \mathrm{DBH}$.

Wood biomass $\left(\mathrm{Mg} \mathrm{ha}^{-1}\right.$ ) was estimated for all trees measured in the inventories, using multiplicative relationship between underbark Volume $\left(\mathrm{V}, \mathrm{m}^{3}\right)$ and Basic Density (BD, $\left.\mathrm{g} \mathrm{cm}^{-3}\right)$. Volume was estimated fitting linearized model of Schumacher \& Hall (1933) (Table 1). At the age of 101 months, $6 \mathrm{~cm}$ thick discs were removed at $0 \%$ (base), $25 \%, 50 \%, 75 \%$ and $100 \%$ (top) of commercial height in one sample tree (the one with mean square diameter ) per experimental unit, totaling 15 trees. From each disc, opposite wedges were obtained, which were used to determine $\mathrm{BD}$ according with water immersion method. The BD for wood biomass estimation ranged from 0.518 to $0.567 \mathrm{~g} \mathrm{~cm}^{-3}$ between spacings.

In the same sample trees, it was measured: Leaf Area (LA), Leaf Perimeter (LP), Specific Leaf Area (SLA), leaves number and leaves biomass. LA and LP were obtained with leaf area meter (Cl-203, CID Inc., USA) of 10 leaves collected in each third of the canopy (upper, middle and lower), adding up to 30 units per canopy. Leaves were collected from the fifth insertion of branches, which were in the center of thirds. The leaves were dried at $65^{\circ} \mathrm{C}$ until constant weight in a oven with forced air circulation and, from the dry biomass, specific leaf area was calculated using the formula: 
$S L A=L A \cdot D M^{-1}$ (eq 1), where DM represents foliar dry mass. LA, LP and SLA data were submitted to Pearson correlation analysis. Leaves number per hectare was estimated as a function of number versus biomass ratio of leaves sampled. To obtain leaves biomass, this component was weighed in field and subsamples were collected to obtain dry mass.

Table 1. Equations used to estimate underbark volume and average values found for Basic Density (BD) of eucalypt in different planting spacings

\begin{tabular}{cccc}
\hline Spacings & Equations & $\bar{R}^{2}$ & $\mathrm{BD}\left(\mathrm{g} \mathrm{cm}^{-3}\right)$ \\
\hline $3.0 \times 0.5 \mathrm{~m}$ & $\operatorname{LnV}=-9.966^{*}+2.278^{*} \mathrm{LnDBH}+0.702^{*} \mathrm{LnH}$ & 0.995 & $0.524 \pm 0.006$ \\
$3.0 \times 1.0 \mathrm{~m}$ & $\operatorname{LnV}=-10.103^{*}+1.958^{\circ} \mathrm{LnDBH}+0.987^{*} \mathrm{LnH}$ & 0.991 & $0.554 \pm 0.001$ \\
$3.0 \times 1.5 \mathrm{~m}$ & & 0.994 & $0.559 \pm 0.003$ \\
$3.0 \times 2.0 \mathrm{~m}$ & $\operatorname{LnV}=-10.579^{*}+1.745^{*} \mathrm{Ln} D B H+1.309^{*} \mathrm{LnH}$ & 0.989 & $0.564 \pm 0.003$ \\
$3.0 \times 3.0 \mathrm{~m}$ & $\operatorname{LnV}=-10.787^{*}+1.644^{*} \mathrm{Ln} D B H+1.454^{*} \mathrm{LnH}$ & 0.983 & $0.546 \pm 0.023$ \\
\hline
\end{tabular}

"significant at $5 \%$ probability by t-test; $\mathrm{DBH}(\mathrm{cm}) ; \mathrm{H}(\mathrm{m}) ; \mathrm{V}=$ underbark volume $\left(\mathrm{m}^{3}\right)$; and $\bar{R}^{z}=$ adjusted determination coefficient. Residual standard errors of the equations were lower than $0.1 \mathrm{~m}^{3}$. BD values indicate mean \pm standard deviation, calculated from 3 trees with mean diameter by spacing (totaling 15 units).

The ANN input variables for simultaneous estimation of eco-physiological attributes were numerical (DBH, $\mathrm{H}$ and spacing between plants $(\mathrm{Spa}, \mathrm{m})$ and categorical (ECF: LA $\left(\mathrm{dm}^{2}\right)-1, \mathrm{LP}$ $(\mathrm{m})-2$ and $\left.S L A\left(\mathrm{~cm}^{2} \mathrm{~g}^{-1}\right)-3\right)$. From the generated network, LA, LP and SLA were estimated for all measured trees in the inventories, which average results per plot extrapolated to a hectare unit.

For the wood biomass future projection $\left(B_{2}\right)$, ANN models were looked for from the

functional relations between numerical variables.

$$
B_{2}=f\left(D B H_{1}, H_{1}, L A_{1}, L P_{1}, S L A_{1}, A_{1}, A_{2}, S p a\right)
$$

where: $A_{1}$ (age, months); $\mathrm{DBH}_{1}(\mathrm{~cm}) ; \mathrm{H}_{1}$ $(\mathrm{m})$; $\mathrm{LA}_{1}\left(\mathrm{~m}^{2}\right), \mathrm{LP}_{1}(\mathrm{Km})$ and $\mathrm{SLA}_{1}\left(\mathrm{~cm}^{2} \mathrm{~g}^{-1}\right)$ refer to the current values of these variables; $\mathrm{B}_{2}\left(\mathrm{Mg} \mathrm{ha}^{-1}\right)$ and $A_{2}$ (months) at their future values and Spa (m,) plant spacing. We defined 19 ANN models (Table 2).

Table 2. Identification and inputs used in Artificial Neural Networks (ANN) to estimate eucalypt biomass up to 101 months old

\begin{tabular}{|c|c|c|c|}
\hline ANN & $\mathrm{N}$ & Architecture & Numerical inputs \\
\hline 1 & 60 & MLP 8-5-1 & $\mathrm{A}_{1}, \mathrm{~A}_{2^{\prime}} \mathrm{Spa}, \mathrm{DBH}_{1}, \mathrm{H}_{1}, \mathrm{LA}_{1}, \mathrm{LP}_{1}, \mathrm{SLA} \mathrm{A}_{1}$ \\
\hline 2 & 60 & MLP 7-12-1 & $\mathrm{A}_{1}, \mathrm{~A}_{2}, \mathrm{Spa}, \mathrm{DBH}_{1}, \mathrm{LA}_{1}, \mathrm{LP}_{1}, \mathrm{SLA}$ \\
\hline 3 & 60 & MLP 7-4-1 & $\mathrm{A}_{1}, \mathrm{~A}_{2}, \mathrm{Spa}, \mathrm{H}_{1}, \mathrm{LA}_{1}, \mathrm{LP}_{1}, \mathrm{SLA} \mathrm{A}_{1}$ \\
\hline 4 & 60 & MLP 6-4-1 & $\mathrm{A}_{1}, \mathrm{~A}_{2}, \mathrm{Spa}, \mathrm{LA}_{1}, \mathrm{LP}_{1}, \mathrm{SLA} \mathrm{A}_{1}$ \\
\hline 5 & 60 & MLP 6-10-1 & $A_{1}, A_{2}, S p a, D B H_{1}, L A_{1}, L P_{1}$ \\
\hline 6 & 60 & MLP 6-8-1 & $\mathrm{A}_{1}, \mathrm{~A}_{2}, \mathrm{Spa}, \mathrm{DBH}_{1}, \mathrm{LA}_{1}, \mathrm{SLA}_{1}$ \\
\hline 7 & 60 & MLP 6-3-1 & $A_{1}, A_{2}, S p a, D B H_{1}, L P_{1}, S L A_{1}$ \\
\hline 8 & 60 & MLP 5-11-1 & $A_{1}, A_{2}, S p a, L A_{1}, L P_{1}$ \\
\hline 9 & 60 & MLP 5-6-1 & $\mathrm{A}_{1}, \mathrm{~A}_{2}, \mathrm{Spa}, \mathrm{LA}_{1}, \mathrm{SLA}$ \\
\hline 10 & 60 & MLP 5-7-1 & $\mathrm{A}_{1}, \mathrm{~A}_{2}, \mathrm{Spa}, \mathrm{LP}_{1}, \mathrm{SLA}$ \\
\hline 11 & 60 & MLP 5-9-1 & $\mathrm{A}_{1}, \mathrm{~A}_{2}, \mathrm{Spa}, \mathrm{DBH}_{1}, \mathrm{H}_{1}$ \\
\hline 12 & 60 & MLP 5-4-1 & $\mathrm{A}_{1}, \mathrm{~A}_{2}, \mathrm{Spa}, \mathrm{DBH}_{1}, \mathrm{LA}_{1}$ \\
\hline 13 & 60 & MLP 5-3-1 & $\mathrm{A}_{1}, \mathrm{~A}_{2}, \mathrm{Spa}, \mathrm{DBH}_{1}, \mathrm{LP}_{1}$ \\
\hline 14 & 60 & MLP 5-3-1 & $\mathrm{A}_{1}, \mathrm{~A}_{2}, \mathrm{Spa}, \mathrm{DBH}_{1}, \mathrm{SLA}_{1}$ \\
\hline 15 & 60 & MLP 4-7-1 & $\mathrm{A}_{1}, \mathrm{~A}_{2}, \mathrm{Spa}, \mathrm{DBH}_{1}$ \\
\hline 16 & 60 & MLP 4-5-1 & $A_{1}, A_{2}, S p a, H_{1}$ \\
\hline 17 & 60 & MLP 4-10-1 & $\mathrm{A}_{1}, \mathrm{~A}_{2}, \mathrm{Spa}, \mathrm{LA}_{1}$ \\
\hline 18 & 60 & MLP 4-3-1 & $A_{1}, A_{2}, S p a, L P_{1}$ \\
\hline 19 & 60 & MLP 4-3-1 & $\mathrm{A}_{1}, \mathrm{~A}_{2}, \mathrm{Spa}, \mathrm{SLA}$ \\
\hline
\end{tabular}

Feedforward networks trained through the backpropagation algorithm were employed. Data normalization and equalization were realized in all pre-processing. The data was randomly divided into training groups $180 \%$ of samples) and validation (20\%), mutually exclusive (Holdout method).

Two thousand ANN of the Multilayer Perceptron (MLP) type were trained: 100 for estimation of eco-physiological attributes and 
1900 for projection of wood biomass (100 for each functional relation). From these ANN, one was selected per functional relationship based on deviations between observed and estimated values. We chose MLP due to its ability to solve greater complex problems in input space, which increases the number of adjusted parameters (Braga et al., 2007). The layers amount and of neurons per layer was optimized by Intelligent Problem Solver (IPS) tool of Statistica 7.0 software (Statsoft, 2007).

Points that extrapolated the general trend, in each planting spacing, were not removed in order to verify networks' ability to deal with outliers. Accuracy assessment and comparison between phases of training and validation of networks were based on the correlation coefficient, relative error, Root Mean Square Error (RMSE,\%), bias (\%) and visual analysis of dispersion graphs and distribution of percentage frequency of residues. Estimated and observed values were compared among themselves by paired t-test at $5 \%$ significance, as suggested by Gorgens et al. (2009), Lafetá et al. (2014) and Cabacinha \& Lafetá (2017).
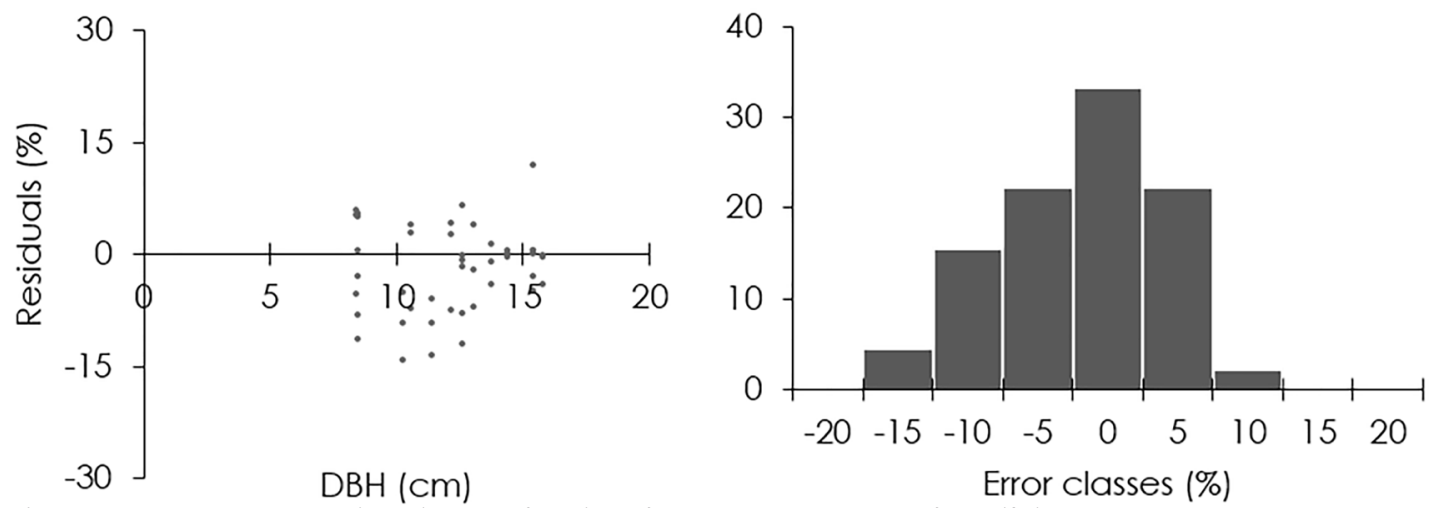

Figure 1. Percentage errors dispersion as a function of DBH and errors classes for artificial neural network constructed to eco-physiological attributes estimate (leaf area, leaf perimeter and specific leaf area) of eucalypt at 101 months old.

Eco-physiological attributes estimates from ANN generalization were able to discriminate differences between spacing as a function of age (Figure 2). This fact has great practical importance, since it enables to make inferences related to established stands competition in different planting densities, as well as potential inputs for mechanistic models adjustment of growth and production. Leaf area, leaf perimeter and specific leaf area increased as planting density and DBH increased, although
All statistical analyzes were performed using with the help of Statistica 7.0 software (Statsoft, 2007).

\section{Results and Discussion}

The artificial neural network structure for eco-physiological attributes estimation was 6-81 (neurons number in input, intermediate and output layers, respectively) with exponential activation functions in intermediate and output layers. In view of eco-physiological interaction complexity and of plant growth, the accuracy was considered satisfactory. Training and validation phases presented around $6.58 \%$ RMSE and $0.48 \%$ Bias. Distribution behavior of percent residuals was homocedastic, concentrating deviations between -12.5 to $+7.5 \%$ (Figure 1). This interval was acceptable and it is in accordance with observed for projections of dendrometric attributes of $\pm 12.5 \%$ error for the projections of DBH, total height and eucalypt volume (Binoti, 2010 ) and up to $\pm 17.5 \%$ for height estimation in pine and eucalypt plantations (Campos et al., 2016), using ANN. 

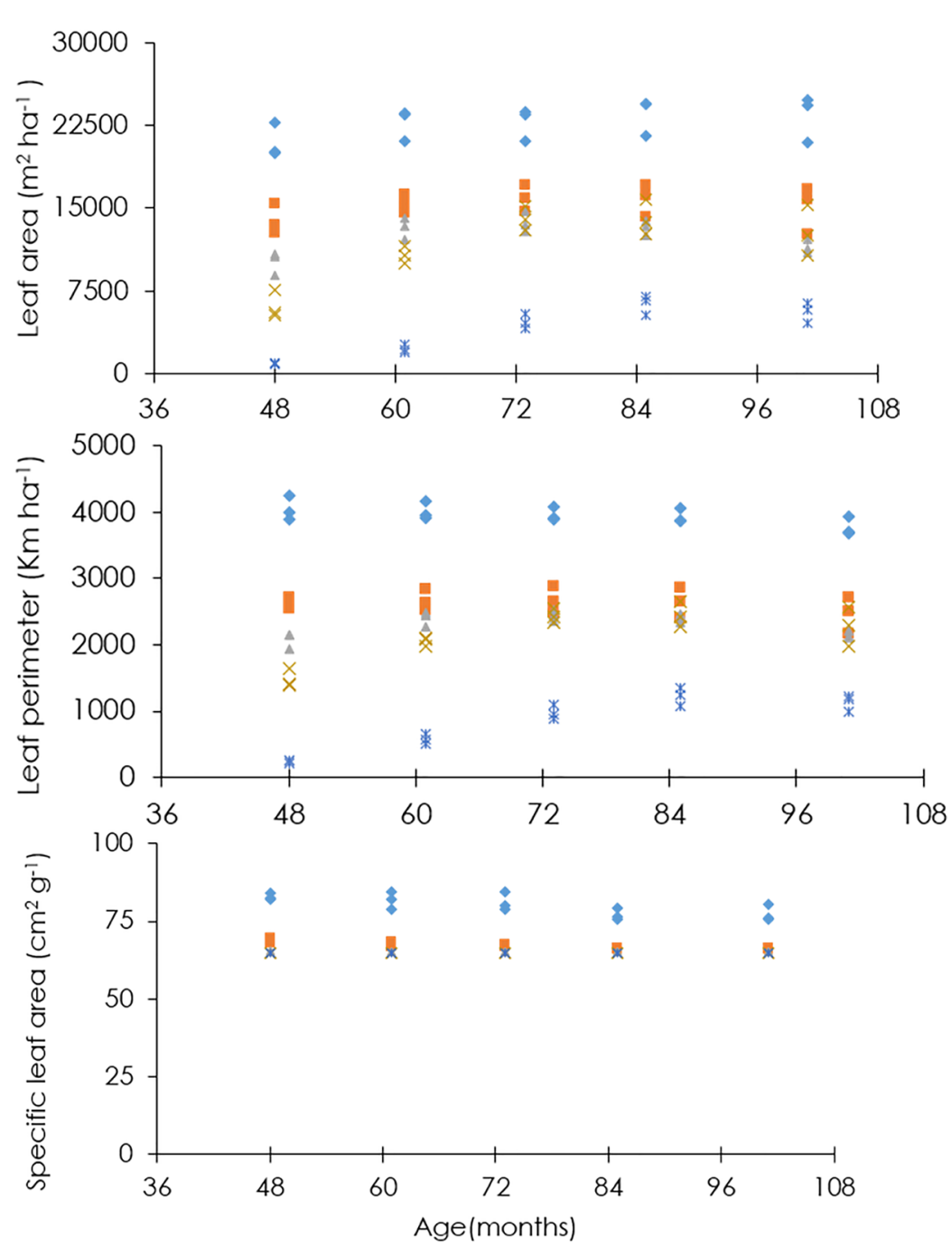

$3.0 \times 0.5 \mathrm{~m}=3.0 \times 1.0 \mathrm{~m} \approx 3.0 \times 1.5 \mathrm{~m} \times 3.0 \times 2.0 \mathrm{~m} \times 3.0 \times 3.0 \mathrm{~m}$

Figure 2. Eco-physiological attributes estimates of eucalypt plants, per hectare, through artificial neural networks throughout ages, grown at different spacings.
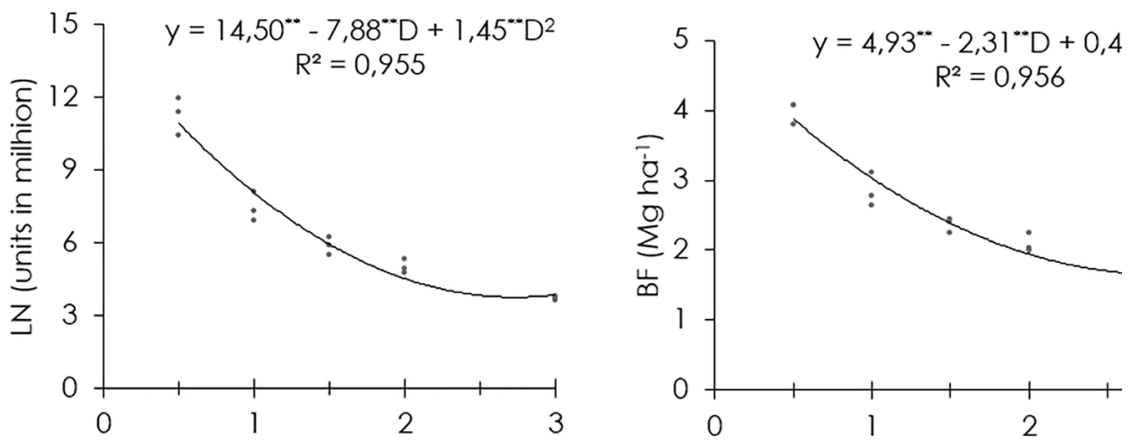

Figure 3. Number (LN) and biomass (LB) of eucalypt plants leaves, per hectare, as a function of distance between plants (D) at 101 months old. "significant at 5\% probability by t-test.

The greater specific leaf area in smaller spacings may be a plant morphological response to compensate greater shading between leaves imposed by competition, which begins with canopies contact. Similarly, Ferreira et al. (2016) studying Bertholletia excelsa Bonpl. plantations to identify spatial and temporal factors effects on leaf attributes, observed a greater specific leaf area in leaves subjected to shading. It is important to note that both perimeter and leaf area can be regulated by environmental variables such as temperature, precipitation and 
light intensity (Vieira et al., 2014; Ferreira et al., 2016). As it reduces spacing, trees tend to get smaller due to increased competition. In general, trees height and diameter growth, per hectare, correlated negatively with the eco-physiological attributes (Table 3). Correlations were significant ( $p<0.05$ ), the highest value (in modulus) was observed between DBH and leaf perimeter (I$0,851^{*} \mid 1$

Table 3. Pearson correlation coefficients between dendrometric variables, conventionally measured in forest inventories, and eucalyptus eco-physiological variables

\begin{tabular}{cccc}
\hline Variables & LA & LP & SLA \\
\hline DBH & $-0.819^{*}$ & $-0.851^{*}$ & $-0.789^{*}$ \\
H & $-0.637^{*}$ & $-0.686^{*}$ & $-0.788^{*}$ \\
\hline
\end{tabular}

ANN for wood biomass estimation showed a predominance of non-linear activation functions in intermediate layers (Table 4). According to Braga et al. (2007), this behavior allows successive layers composition to have greater predictive capacity, facilitating generation of global receptive fields by
MLP. Considering dendrometric and ecophysiological inputs (ANNs 15 to 19), greater complexity expressed by neurons number in the intermediate layer was observed for leaf area. ANNs 7, 13, 14, 18 and 19 were the simplest, as it can be observed by smaller neurons number in their architecture.

Table 4. Artificial Neural Networks (ANN) characteristics built to eucalypt wood biomass projection up to 101 months old

\begin{tabular}{|c|c|c|c|c|c|c|}
\hline \multirow{2}{*}{ ANN } & \multirow{2}{*}{ Architecture } & \multicolumn{2}{|c|}{ Correlation coefficients } & \multirow{2}{*}{ Cycles } & \multicolumn{2}{|c|}{ Activation Functions } \\
\hline & & Training & Validation & & Intermediate & Output \\
\hline 1 & MLP 8-5-1 & $0.9846^{*}$ & $0.9382^{*}$ & 878 & Logistic & Exponentia \\
\hline 2 & MLP 7-12-1 & $0.9730^{*}$ & $0.9403^{*}$ & 121 & Identity & Identity \\
\hline 3 & MLP 7-4-1 & $0.9660^{*}$ & $0.9063^{*}$ & 235 & Tangential & Logistic \\
\hline 4 & MLP 6-4-1 & $0.9529^{*}$ & $0.8542^{*}$ & 709 & Tangential & Identity \\
\hline 5 & MLP 6-10-1 & $0.9494^{*}$ & $0.9399^{*}$ & 83 & Identity & Exponentia \\
\hline 6 & MLP 6-8-1 & $0.9702^{*}$ & $0.9474^{*}$ & 451 & Logistic & Logistic \\
\hline 7 & MLP 6-3-1 & $0.9722^{*}$ & $0.9614^{*}$ & 10000 & Exponential & Exponentia \\
\hline 8 & MLP 5-11-1 & $0.9112^{*}$ & $0.7869^{*}$ & 2321 & Logistic & Exponentia \\
\hline 9 & MLP 5-6-1 & $0.9220^{*}$ & $0.7851^{*}$ & 771 & Tangential & Tangential \\
\hline 10 & MLP 5-7-1 & $0.9145^{*}$ & $0.5769^{*}$ & 517 & Logistic & Tangential \\
\hline 11 & MLP 5-9-1 & $0.9657^{*}$ & $0.9486^{*}$ & 319 & Logistic & Logistic \\
\hline 12 & MLP 5-4-1 & $0.9757^{*}$ & $0.9493^{*}$ & 215 & Logistic & Tangential \\
\hline 13 & MLP 5-3-1 & $0.9715^{*}$ & $0.9262^{*}$ & 264 & Logistic & Identity \\
\hline 14 & MLP 5-3-1 & $0.9747^{*}$ & $0.9485^{*}$ & 395 & Logistic & Identity \\
\hline 15 & MLP 4-7-1 & $0.9769^{*}$ & $0.9635^{*}$ & 10000 & Exponential & Exponentia \\
\hline 16 & MLP 4-5-1 & $0.9608^{*}$ & $0.8383^{*}$ & 10000 & Exponential & Exponentia \\
\hline 17 & MLP 4-10-1 & $0.9033^{*}$ & $0.7802^{*}$ & 473 & Logistic & Logistic \\
\hline 18 & MLP 4-3-1 & $0.8873^{*}$ & $0.7241^{*}$ & 215 & Logistic & Tangential \\
\hline 19 & MLP 4-3-1 & $0.8698^{*}$ & $0.8207^{*}$ & 1177 & Exponential & Logistic \\
\hline
\end{tabular}

Networks complexity was not necessarily caused by a greater number of times in which training set was presented to architecture, since network 7 had few neurons in intermediate layer (3 units) and more cycles (10000) when compared to ANNs 5 and 17. Cycles and number neurons in the intermediate layer had a correlation coefficient of $-0.15^{\text {ns }}$. Most correlation coefficients were above 0.80 . The difference between training and validation coefficients were, on average, 0.08, being higher in ANN 10 (difference of 0.34). It is likely that this difference found in ANN 10 related to higher variation amplitudes of relative error during the validation phase; in this network, the ratio between relative error amplitudes of validation and training phases was 1.43. In addition, performance of training and validation phases can be influenced by neurons and cycles number (Braga et al., 2007; Maeda et al., 2009). 
All networks for wood biomass projection presented no statistical significance by t-test ( $p>0.05$ ) and no bias in the training phase, with Iow Bias, RMSE and error amplitude (Table 5). Obtained estimates with network 5 were not statistically significant. This may be related to an underfitting generated by a small number of cycles (Table 4), preventing network from achieving its best performance (Cabacinha \& Lafetá, 2017). Underfitting phenomenon is common and related to network subtraining, which does not converge adequately during adjustment of its synaptic weights (Braga et al., 2007).

Table 5. Artificial Neural Networks (ANN) accuracy built to eucalypt wood biomass projection up to 101 months old

\begin{tabular}{|c|c|c|c|c|c|c|c|}
\hline \multirow{2}{*}{ ANN } & \multirow{2}{*}{ Phases } & \multirow{2}{*}{ RMSE (\%) } & \multirow{2}{*}{ Bias (\%) } & \multicolumn{3}{|c|}{ Relative errors (\%) } & \multirow{2}{*}{$\begin{array}{c}\text { t-test } \\
P\end{array}$} \\
\hline & & & & Maximum & Average & Minimum & \\
\hline \multirow{2}{*}{1} & Training & 2.41 & -0.11 & 9.69 & 0.23 & -4.52 & 0.7574 \\
\hline & Validation & 3.97 & 1.00 & 4.32 & -0.93 & -11.09 & 0.3835 \\
\hline \multirow{2}{*}{2} & Training & 3.23 & 0.15 & 9.31 & 0.04 & -8.64 & 0.7438 \\
\hline & Validation & 3.98 & 1.34 & 2.40 & -1.24 & -10.40 & 0.2395 \\
\hline \multirow{2}{*}{3} & Training & 3.57 & 0.13 & 10.31 & 0.05 & -11.11 & 0.7942 \\
\hline & Validation & 4.66 & 0.86 & 8.84 & -0.63 & -9.40 & 0.5299 \\
\hline \multirow{2}{*}{4} & Training & 4.16 & 0.00 & 12.74 & 0.20 & -8.41 & 1.0000 \\
\hline & Validation & 7.12 & 0.35 & 9.42 & -0.40 & -13.88 & 0.8680 \\
\hline \multirow{2}{*}{5} & Training & 4.30 & 0.00 & 10.61 & 0.21 & -11.16 & 0.9976 \\
\hline & Validation & 4.72 & 2.60 & 1.59 & -2.50 & -11.79 & 0.0401 \\
\hline \multirow{2}{*}{6} & Training & 3.38 & 0.18 & 9.89 & 0.02 & -8.92 & 0.7197 \\
\hline & Validation & 3.97 & 1.66 & 2.89 & -1.61 & -9.99 & 0.1338 \\
\hline \multirow{2}{*}{7} & Training & 3.21 & -0.03 & 10.19 & 0.17 & -9.35 & 0.9430 \\
\hline & Validation & 3.31 & 0.66 & 3.83 & -0.70 & -7.85 & 0.4920 \\
\hline \multirow{2}{*}{8} & Training & 5.65 & -0.10 & 13.50 & 0.45 & -8.64 & 0.8988 \\
\hline & Validation & 7.93 & 3.54 & 6.98 & -3.14 & -12.99 & 0.1082 \\
\hline \multirow{2}{*}{9} & Training & 5.31 & 0.01 & 13.64 & 0.26 & -8.98 & 0.9922 \\
\hline & Validation & 8.28 & 3.61 & 7.44 & -3.28 & -16.63 & 0.1178 \\
\hline \multirow{2}{*}{10} & Training & 5.55 & 0.05 & 12.84 & 0.26 & -9.56 & 0.9532 \\
\hline & Validation & 10.60 & 2.65 & 16.26 & -2.16 & -16.42 & 0.3884 \\
\hline \multirow{2}{*}{11} & Training & 3.65 & 0.24 & 11.04 & -0.02 & -8.90 & 0.6467 \\
\hline & Validation & 4.07 & 1.97 & 2.41 & -1.89 & -9.93 & 0.0773 \\
\hline \multirow{2}{*}{12} & Training & 3.04 & 0.20 & 10.73 & -0.06 & -9.22 & 0.6554 \\
\hline & Validation & 3.67 & 0.93 & 4.21 & -0.91 & -9.04 & 0.3823 \\
\hline \multirow{2}{*}{13} & Training & 3.25 & 0.00 & 9.21 & 0.12 & -7.78 & 1.0000 \\
\hline & Validation & 4.40 & 1.40 & 3.84 & -1.29 & -10.68 & 0.2655 \\
\hline \multirow{2}{*}{14} & Training & 3.06 & 0.00 & 10.83 & 0.11 & -9.02 & 1.0000 \\
\hline & Validation & 3.67 & 0.89 & 5.43 & -0.86 & -8.41 & 0.4028 \\
\hline \multirow{2}{*}{15} & Training & 2.93 & -0.04 & 10.77 & 0.16 & -9.48 & 0.9292 \\
\hline & Validation & 3.49 & 1.25 & 3.66 & -1.30 & -9.39 & 0.2084 \\
\hline \multirow{2}{*}{16} & Training & 3.80 & 0.00 & 13.58 & 0.16 & -7.62 & 0.9982 \\
\hline & Validation & 6.74 & 2.78 & 10.60 & -2.44 & -15.50 & 0.1408 \\
\hline \multirow{2}{*}{17} & Training & 5.89 & -0.07 & 12.68 & 0.44 & -9.73 & 0.9359 \\
\hline & Validation & 7.77 & 3.09 & 7.28 & -2.70 & -11.93 & 0.1576 \\
\hline \multirow{2}{*}{18} & Training & 6.33 & 0.01 & 13.04 & 0.39 & -12.33 & 0.9946 \\
\hline & Validation & 8.86 & 3.67 & 7.89 & -3.20 & -14.77 & 0.1393 \\
\hline \multirow{2}{*}{19} & Training & 6.76 & -0.02 & 12.22 & 0.48 & -12.25 & 0.9857 \\
\hline & Validation & 7.18 & 3.19 & 8.71 & -2.79 & -11.83 & 0.1097 \\
\hline
\end{tabular}

Although the ANNs presented a good training and a worse validation, RMSE and Bias varied little between processing phases and relative amplitudes errors were, on average, $20.65 \%$ training and $17.89 \%$ validation (Table 5). Due to smaller neurons number in the intermediate layer, higher correlation coefficient in validation phase and precision statistics values, ANNs 7, 13, 14 and 15 were chosen for subsequent graphical analyzes (Figure 4).

Noise absence observed in Figure 4 demonstrated ANN ability to deal with outliers during the process of adjusting its weights through the learning algorithm. After network selection, 


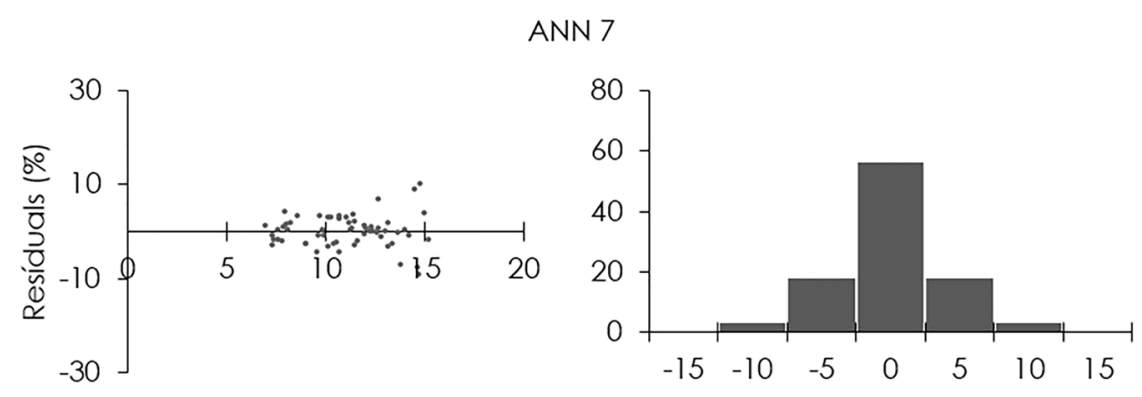

ANN 13
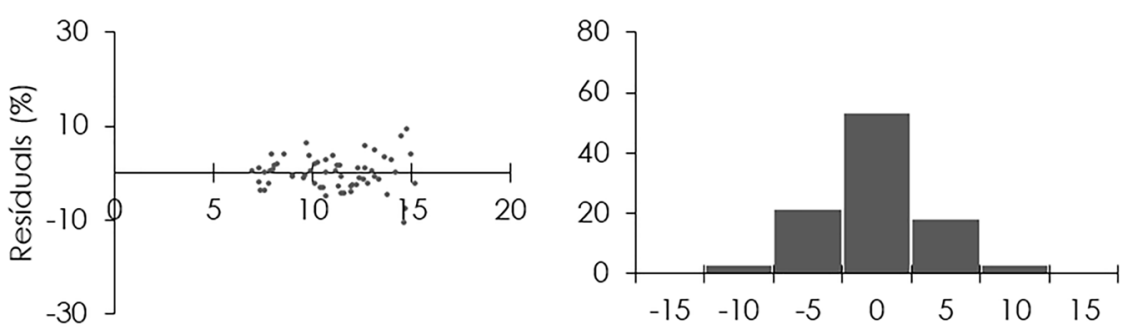

ANN 14
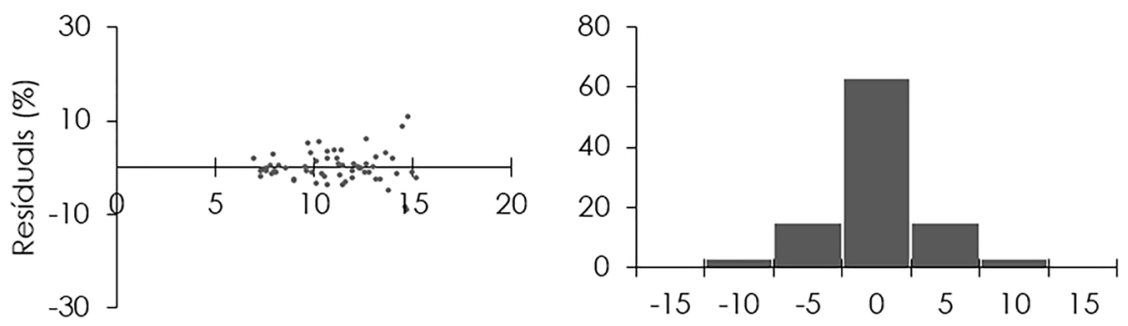

ANN 15
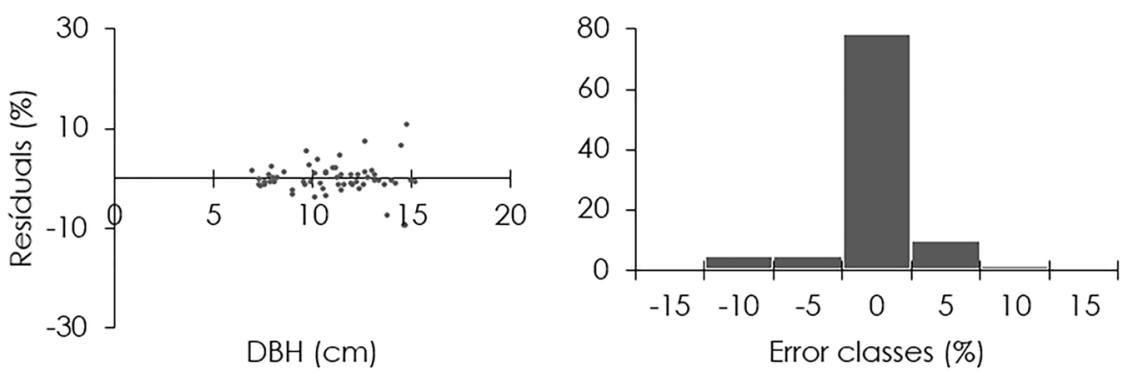

Figure 4. Percentage errors dispersion as a function of DBH and errors classes for Artificial Neural Networks (ANN) built to eucalypt wood biomass projection up to 101 months old.

future projection of wood biomass production was carried out considering current age of 48 months and graphical analysis of dispersion between observed and estimated values (Figure 5). Wood biomass prognosis with ANNs 7, 13, 14 and 15 did not generate similar projections. ANNs 7 and 15 did not generate biologically realistic estimates, disagreeing with observed values. This was probably consequence of excessive memorization of training data $(10,000$ cycles $)$ or overfitting.

ANNs 13 and 14 showed less estimates dispersion and better projections along age.
These networks were the only ones that exhibited logistic and identity activation functions in the intermediate and output layers, respectively. The combination of both activation functions may have favored network predictive capability with MLP architecture. However, a disadvantage observed in network 14 was loss in accuracy and underestimation of wood biomass estimated from 73 months, not capturing actual reduction of growth rate. ANN 13, which used DBH and leaf perimeter in its functional relationship, was able to learn and generalize assimilated knowledge to biomass projection, demonstrating that it 

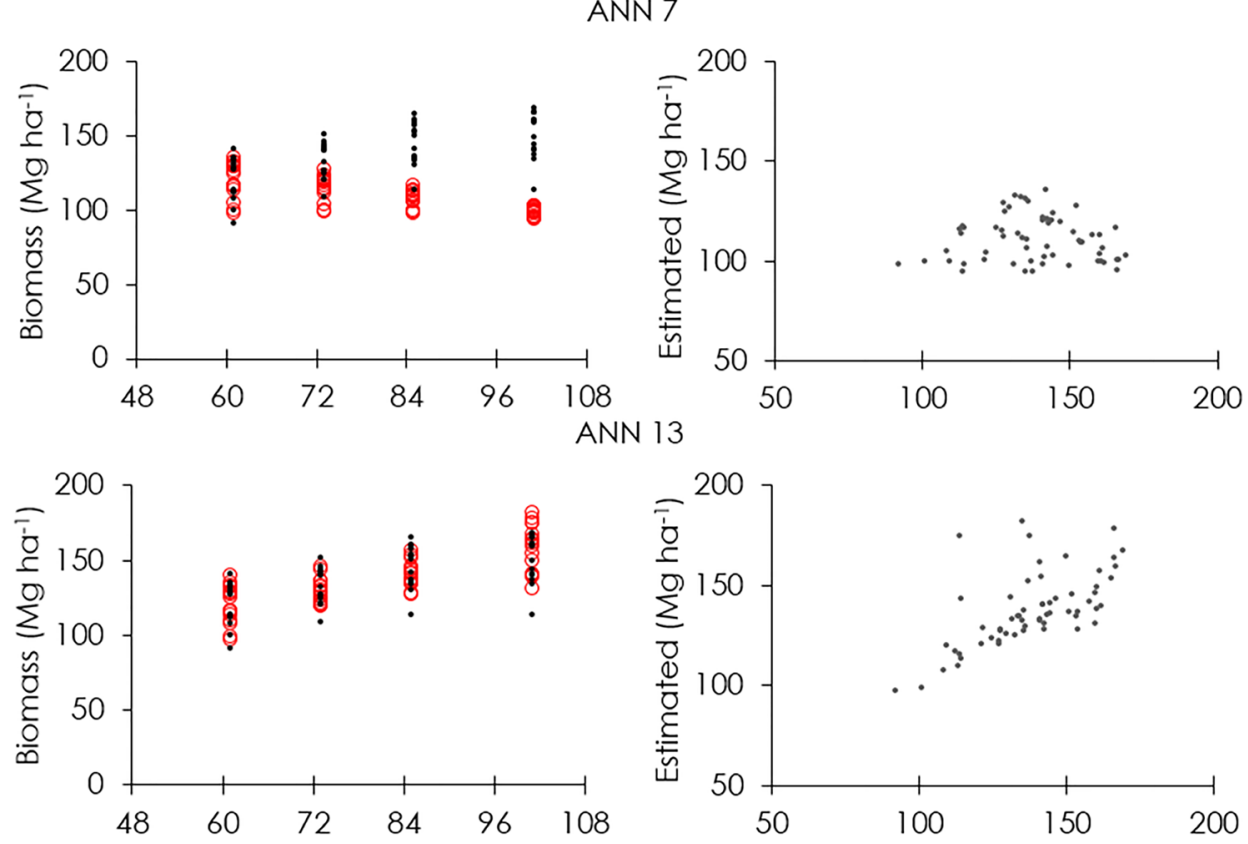

ANN 14
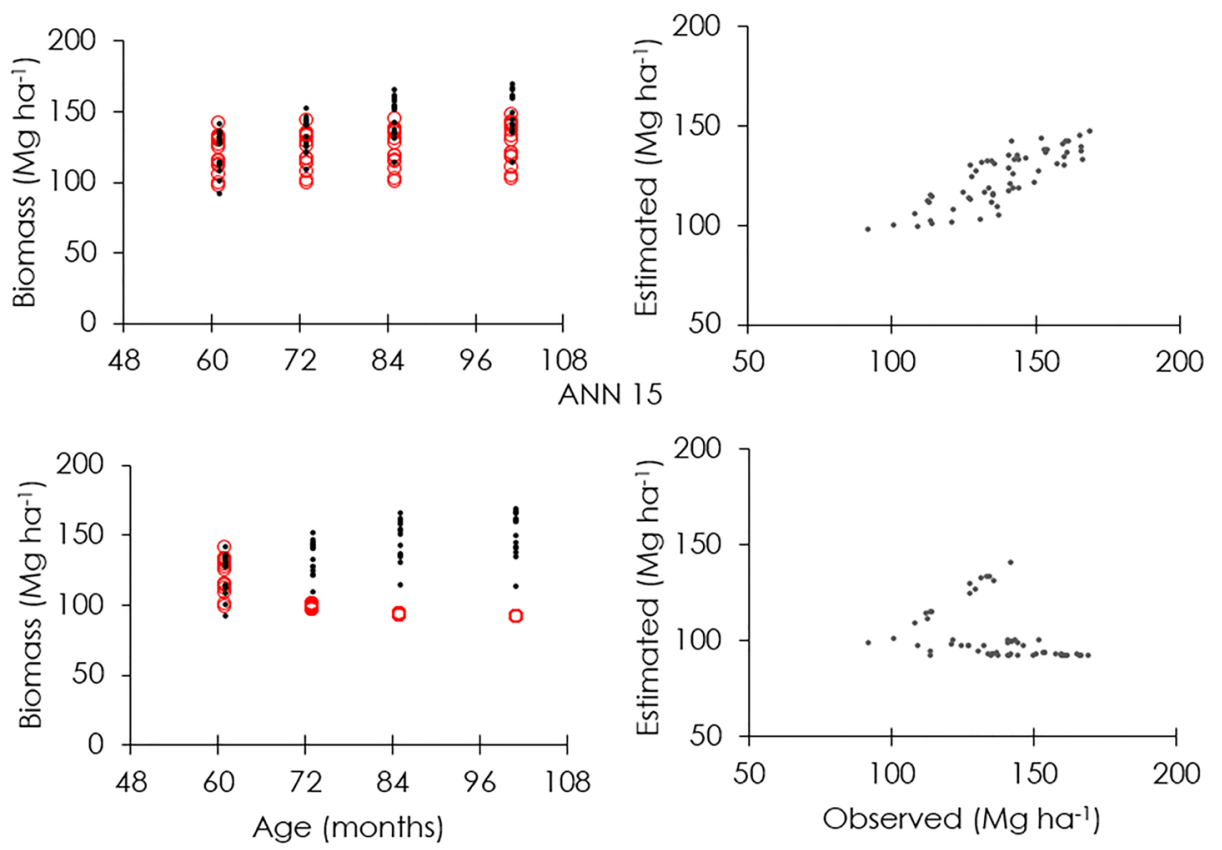

- Estimated . Observed

Figure 5. Future projection of eucalypt wood biomass production considering current age of 48 months and dispersion between observed and estimated values.

can capture biological realism of a cumulative production curve, characterized by a sigmoidal behavior.

\section{Conclusions}

Artificial neural network modeling, with Multilayer Perceptron architecture and trained by backpropagation algorithm, can be used with good precision to estimate eucalypt wood biomass at different planting spacings.
Artificial neural networks technique can be recommended for prediction of eucalypt wood biomass, using diameter-at-breast-height and leaf perimeter in set of predictor variables.

Dendrometric and eco-physiological predictors variables combination can be a viable alternative to improve quality of eucalypt wood biomass estimates. 


\section{Acknowledgments}

To the CAPES, CNPq, Aperam Bioenergia and UFVJM for all assistance, financial assistance and support for research development.

\section{References}

Alcorn, P.J., Bauhus, J., Thomas, D.S., James, R.N., Smith, R.G.B., Nicotra, A.B. 2008. Photosynthetic response to green crown pruning in young plantation-grown Eucalyptus pilularis and E. cloeziana. Forest Ecology and Management 255: 3827-3838.

Almeida, A.C., Soares, J.V., Lansberg, J.J., Rezende, G.D. 2007. Growth and water balance of Eucalyptus grandis hybrids plantations in Brazil during a rotation for pulp production. Forest Ecology and Management 251: 10-21.

Binoti, M.L.M.S. 2010. Redes neurais artificiais para prognose da produção de povoamentos não desbastados de eucalipto. 54f. (M.Sc. Dissertation) - Universidade Federal de Viçosa, Viçosa, Brasil.

Binoti, M.L.M.S., Leite, H.G., Binoti, D.H.B., Gleriani, J.M. 2015. Prognose em nível de povoamento de clones de eucalipto empregando redes neurais artificiais. Cerne 21: 97-105.

Braga, A.P., Carvalho, A.C.P.L.F., Ludermir, T.B. 2007. Redes neurais artificiais: teoria e aplicações. LTC, Rio de Janeiro, Brasil. 226 p.

Cabacinha, C.D., Lafetá, B. O. 2017. Floristic diversity and equitability in forest fragments using artificial neural networks. Ciência Florestal 27: 143-152.

Campos, B.P.F., Silva, G.F., Binoti, D.H.B., Mendonça, A.R., Leite, H.G. 2016. Predição da altura total de árvores em plantios de diferentes espécies por meio de redes neurais artificiais. Pesquisa Florestal Brasileira 36: 375-385.

Campos, J.C.C., Leite, H.G. 2013. Mensuração Florestal. UFV, Viçosa, Brasil. 605 p.

Costa, A.M., Curi,N., Araújo, E.F., Marques, J.J., Menezes, M.D. 2009. Avaliação do risco de anoxia para o cultivo do eucalipto no Rio Grande do Sul utilizando-se levantamento de solos. Scientia Forestalis 37: 367-375.

Ferreira, M.J., Gonçalves, J. F. C., Ferraz, J.B.S., Santos Junior, U. M., Rennenberg, H. 2016. Clonal variation in photosynthesis, foliar nutrient concentrations, and photosynthetic nutrient use efficiency in a Brazil Nut (Bertholletia excelsa) plantation. Forest Science 62: 323-332.

Gorgens, E.B., Leite, H.G., Santos, H.N., Gleriani, J.M. 2009. Estimação do volume de árvores utilizando redes neurais artificiais. Revista Árvore 33: 1141-1147.

INMET, Instituto Nacional de Meteorologia. 2010. http://www.inmet.gov.br/<Acesso em 16 out. 2010>.

KÖPPEN, W. 1936. Das geographische System der Klimate. Gerbrüder Bornträger, Berlin, 44 p.

Lafetá, B.O., Santana, R.C., Nogueira, G.S., Penido, T.M.A., Chaves, C.M.M.B., Mucida, D.P. 2014. Artificial neural networks to estimate nutrient use efficiency in eucalypt. Australian Journal of Basic and Applied Sciences 8: 259-264.

Maeda, E.E., Formaggio, A.R., Shimabukuro, Y.E., Arcoverde, G.F.B., Hansen, M.C. 2009. Predicting forest fire in the Brazilian Amazon using MODIS imagery and artificial neural networks. International Journal of Applied Earth Observation and Geoinformation 11: 265-272.

Maire, G., Marsden, C., Verhoef, W., Ponzoni, F.J., Seen, D., Bégué, A., Stape, J.L., Nouvellon, Y. 2011. Leaf area index estimation with MODIS reflectance time series and model inversion during full rotations of Eucalyptus plantations. Remote Sensing of Environment 115: 586-599.

Merchant, A., Peuke, A.D., Keitel, C., Macfarlane, C., Warre $\delta$ C.R., Adams, M.A. 2010. Phloem sap and leaf ${ }^{13} \mathrm{C}$, carbohydrates, and amino acid concentrations in Eucalyptus globulus change systematically according to flooding and water deficit treatment. Journal of Experimental Botany 61: 1785-1793.

Miehle, P., Battaglia, M., Sands, P.J., Forrester, D.I., Feikema, P.M., Livesley, S.J., Morris, J.D., Arndt, S.K. 2009. A comparison of four process-based models and a statistical regression model to predict growth of Eucalyptus globulus plantations. Ecological Modelling 220: 734-746.

Montaldo, N., Albertson, J.D., Mancini, M. 2008. Vegetation dynamics and soil water balance in a water-limited Mediterranean ecosystem on Sardinia, Italy. Hydrology and Earth System Sciences 12: 1257-1271.

Nascimento, Â.M.P., Paiva, P.D.O., Nery, F.C., Souza, R.R., Manfredini, G.M., Almeida, E.F.A. 2015. Influência do espaçamento de plantio e luminosidade no desenvolvimento de bastãodo-imperador. Revista Brasileira de Ciências Agrárias 10: 230-236.

Nouvellon, Y., Laclau, J., Epron, D., Kinana, A., Mabiala, A., Roupsard, O., Bonnefond, J., Maire, G., Marsden, C., Bontemps, J., Saint-André, L. 2010. Within-stand and seasonal variations of specific leaf area in a clonal Eucalyptus plantation in the Republic of Congo. Forest Ecology and Management 259: 1796-1807. 
Pulrolnik, K., Barros, N.F., Silva, I.R., Novais, R.F., Brandani, C.B. 2009. Estoques de carbono e nitrogênio em frações lábeis e estáveis da matéria orgânica de solos sob eucalipto, pastagem e cerrado no Vale do Jequitinhonha-MG. Revista Brasileira de Ciência do Solo 33: $1125-1136$.

Schumacher, F.X., Hall, F.S. 1933. Logarithmic expression of timber-tree volume. Journal of Agricultural Research 47: 719-734.

Statsoft Inc. 2007. Statistica (data analysis software system), version 7. Statsoft, Tulsa, USA.

Vieira, W.L., Boeger, M.R.T., Cosmo, N.L., Coan, A.I. 2014. Leaf morphological plasticity of tree species from two developmental stages in Araucaria forest. Brazilian Archives of Biology and Technology 57: 476-485.

Zanuncio, A.J.V., Carvalho, A.G., Silva, L.F., Carneiro, A.C.O., Colodette, J.L. 2016. Artificial neural networks as a new tool for assessing and monitoring wood moisture content. Revista Árvore 40: 543-549. 